\title{
An Effective End-User Knowledge Concern Training Method in Enterprise Resource Planning (ERP) Based on Critical Factors $(\mathrm{CFs})$ in Malaysian SMEs
}

\author{
Ali Noudoostbeni (Corresponding author) \\ Dep. Information Science, Faculty of computer Science and Information Technology \\ University Malaya, Kuala Lumpur, Malaysia \\ Tel: 60-1-7242-4951_E-mail: Ali_beni62@yahoo.com \\ Noor Azina Ismail \\ Dep. Applied Statistics, Faculty of Economics and Administration \\ University Malaya, Kuala Lumpur, Malaysia \\ Tel: 60-1-9230-6423 E-mail: nazina@um.edu.my \\ Hashem Salarzadeh Jenatabadi \\ Dep. Applied Statistics, Faculty of Economics and Administration \\ University Malaya, Kuala Lumpur, Malaysia \\ Tel: 60-1-7870-6467 E-mail: hashem.salarzadeh@gmail.com \\ Norizan Mohd Yasin \\ Dep. Information Science, Faculty of computer Science and Information Technology \\ University Malaya, Kuala Lumpur, Malaysia \\ Tel: 60-3-7967-6353 E-mail: norizan@um.edu.my
}

\begin{abstract}
Nowadays, many companies are using Enterprise Resource Planning (ERP) as one of the comprehensive integrated systems. This study focuses on various aspects of the ERP utilized in Small and Medium Enterprises (SMEs) in Malaysia in three phases. The success and the failure factors of ERP in SMEs were identified in the first phase. A comparison between different ERP training methods was carried out in the second phase. Based on the findings in the first two phases, a new training method was developed in the third phase, so that ERP users may have a more effective ERP training system in the SMEs in Malaysia. The research method applied to the current research is case study in which the required data was collected from different SMEs in Malaysia. The data collection was mainly based on the surveys and interviews, and the results of the data analysis were used to improve a client-based training system. The achieved results indicate that the application of this kind of system which is based on a combination of On-the-job training and Computer-based training system would considerably reduce the time and money spent on learning and training plans, while, at the same time, it would increase the user's proficiency and knowledge concerning in the ERP system.
\end{abstract}

Keywords: Enterprise resource planning, Small and medium enterprises, ERP critical success and failure factors, Training method

\section{Introduction}

The main objective of the current research is the survey and implementation of ERP in SMEs in Malaysia. Although the ERP systems have achieved some successes in some companies in Malaysian market, the majority of the SMEs seem to have been ignoring the application of this system in their business. Moreover, this study will focus on developing an advanced training system program on the ERP adoptable by and adaptable to 
Malaysian SMEs. The adoption and adaptation of ERP among Malaysian SMEs is a new trend which needs a significant consideration since there is not enough number of enterprises dealing with this issue. Moreover, the "Malaysia, Policies, Incentives and Facilities for SMEs" issued by Ministry of International Trade and Industry (MITI) indicated that the Malaysian government provided a financial assistance scheme as "Grant for ICT Application" for SMEs (MITI, Ministry of International Trade \& Industry, 2002). The scheme provided assistance for purchasing of ERP software for manufacturing and manufacturing related services. The Small and Medium Industries Development Corporation (SMIDEC) is responsible for allocation of this grant.

As stated above, the main purpose of this research is the study of ERP in Malaysian SMEs. This study contains three different phases which will be defined and elaborated in the following sections. The first phase has fifteen success and eight failure factors in the implementation of ERP in Malaysian SMEs. These factors have been studied on the basis of the previous studies. The analysis of the collected data reveals that the "effective training of users and team works", and "poor planning and unsuitable training methods" are the most significant and effective success and failure factors in SMEs respectively. The results of the studies in the first phase support the claim that training is the most important factor in success or failure in ERP systems in Malaysian SMEs. The second phase will study and compare the attributes of two of the training methods among other training methods in the ERP system.

Methods of On-the-Job Training (OJT) and Computer-Based learning are two useful and effective methods in training ERP users. In these methods the strategies are based on the analysis of the previous data and researches. In the third phase of this research, a new method will be introduced for training the ERP users based the achieved results from previous phases. Table 1 depicts the contrasts and complementary results of this research from phase 1 to phase 3 . The elaboration of the above-mentioned phases will follow in the next subsections.

\section{Phase One}

\subsection{Introduction}

As it is obvious, the growth and development of the Information and Communication Technology (ICT) has been moving forward in the recent years with crazy speed. This movement has resulted in the appearance of different industries in the fields of electronics, computer, telecommunication, and the like, which have been involved in the expedition of its moving, in turn. This condition has brought about myriad number of changes through its influence on the functions of the organizations. Enterprise Resource Planning (ERP) has been one of the main businesses that help organizations to manage their resources in the optimally effective fashion. ERP is a multi-module application system which combines the key businesses and the management processes in an enterprise to enhance the efficiency level of the missions and tasks.

In this line, ERP systems allow the firms to manage their businesses with potential benefits reduction of cycle time; faster transactions; better financial management; the laying of the groundwork for e-commerce; and making tacit knowledge explicit (Yi \& Chyan, 2010). On the other hand, Bendoly and Jacobs (2004), Loh and Koh (2004) and Woo (2007), argue that ERP has the required capability to decrease the level of inventory, scale down costs, reduce lead-times, boost productivity, make corporate communication easier and more feasible, improve information and decision making capabilities and customer services. Considering these capabilities and functionalities, Ketikidis et al. (2008) concluded that ERP systems provide the companies with possibilities to raise the competitive advantage of their business and their share in the market. In recent years, the said potential advantages have resulted in a considerable growth in the ERP market. In line with this growth, an increasing number of SMEs have tried to implement and operate these systems (Loh \& Koh, 2004). Although ERP is not as complicated as a mixed information system (Shou \& Ying, 2005), due to high rate of difficulties and failures in implementing the ERP systems, as explained in the review of literature, it can cause some disorders (Jafari, Osman, Yusuf, \& Tang, 2006). Therefore, there are many companies that, due to the high failure rate, are not successful in their ERP implementation projects (Trunick, 1999).

Of course, it is not deniable that at least $90 \%$ of the ERP implementations are usually extended beyond the estimated and allotted budget, or they are often fulfilled later than the scheduled timetable (Martin, 1998). In this regard, two kinds of failures have been distinguished, namely: (1) the total failure, which is a project which has never been actually initiated or launched, or it has been initiated but was immediately abandoned, and, therefore, unfulfilled, and (2) partial failure, that can, especially, be witnessed in the developing countries, refers to a project that has initially been launched successfully but, after sometime, due to various reasons, the implementation fails. In this kind of failure, unlike the previous one, the failure is usually the result of impossibility of sustainability of information system (Yongyi \& Ying, 2005).

In a recent survey, Umble and Michael have identified three main sources that result in the failure of all 
IT-related projects carried out by IT managers (Umble \& Michae, 2002) as follows: (1) poor planning or poor management (77\%), (2) shifts in the business purposes during the project $(75 \%)$, and (3) lack of business management support $(73 \%)$. There are some other possible factors that influence the organizational and managerial decisions, namely, hostile company culture, unsuitable reporting structure, political pressures, vested interests, influences and inappropriate level of management commitment are among them (Yongyi \& Ying, 2005).

Since 1979, there have been academic reactions against the ERP systems implementation issues concentrating on the ERP implementation failures through considering the Success Factors (SFs) (Bullen, 1995). Success Factors (SFs) are factors that determine the success rate of an implementation in an organization. These factors are the most essential ones when a firm needs to achieve its objectives. Success Factors are utilized by managers to assist them to discover and identify the elements that are required to be in the right course to achieve the desired goals (Jafari, Osman, Yusuf, \& Tang, 2006). Hence, these factors have a vital role in the successful implementation of an ERP system in a company. There is myriad number of complicated factors that can influence and help the ERP implementations into either achievement of the desired success or expedite their failure (Umble, Haft, \& Umble, 2003). Therefore, the study and analysis of the factors to know the success factors from the failure ones is an essential task to discover and choose those which lead to success rather than failure (Jing \& Qiu, 2007).

In a joint study, Huang and Palvia (Huang \& Palvia, 2001) have dealt with the challenges that ERP technology encounters in most of the developing countries. As a result of the recent increase in the reliance of SMEs, ERP vendors have turned to this business more than before (Al-Mashari, Zairi, \& Okazawa, 2006). According to different definitions that SMEs have in various regions, the approaches differ from one region to another. One of the definitions, for example, observes SMEs as an enterprise in which fewer than 250 staff members are involved and the annual revenue is less than EUR 40 million or the annual balance-sheet displays a balance less than EUR 27 million (Laukkanen, Sarpola, \& Hallikainen, 2005). However, the secretariat of National SME Development Council of Malaysia has given a different definition of SMEs based on two criteria as following:

(1) Number of the full-time employees

(2) Annual sales turnover

As per this definition, Malaysian firms with fewer than 150 full-time employees and less than RM25 million of annual sales turnovers are distinguished as SMEs. Recently, most of the ERP producers have started recognizing the Small and Medium size enterprises that had been neglected since 2003. There are huge numbers of medium and small companies around the world that are unable to sustain an efficient business. This condition has created an invaluable opportunity for ERP vendors to concentrate on them as an unprecedented ERP market. On the other hand, SMEs are also trying to approach the ERP systems because of the necessity of the information systems integration in their business and the expenses of the relative hardware installation (Laukkanen, Sarpola, \& Hallikainen, 2005).

In general, inconsiderable work has been done so far in Malaysia in connection with the effective success and failure factors in implementing ERP systems, yet no particular work has been done about Malaysian Small and Medium Enterprises (SMEs). Hence, this study tends to focus on this issue as its primary end. As stated above, this research consists of three phases, the first of which specifically focuses on: (1) analyzing the success and failure factors within Malaysian Small and Medium Enterprises, and understanding whether the results comply with the ones in other parts of the world, and (2) finding out the important ERP success and failure factors in Malaysian SMEs.

\subsection{Analyzing the Success and Failure Factors in ERP System Implementation in Malaysian SMEs}

By looking through the literature review by others, some success factors are more highlighted. According to Nah and Lau (2001) who analyzed ten selective articles from (1998-2000) found nine ERP success factors (SFs) listed below:

(1) ERP teamwork and composition (2) Top management support (3) Business plan and vision (4) Effective communication (5) Project management (6) Appropriate business and legacy systems (7) Software development, testing and troubleshooting (8) Effective decision - making (9) Effective training.

Based on another article (Jing \& Qiu, 2007) through analyzing SFs in the process of implementing ERP 13 success factors have been found:

(1) Top management involvement (2) Department's participation (3) Funds support (4) Cooperation between enterprise \& software company (5) Reasonable expectation with definite target (6) Open and honest 
communication (7) Training (8) Group structure (9) Project management (10) Enterprise information management (11) Outsider competition pressure (12) level of the supplier of ERP (13) Service of the supplier of ERP.

In the previous research by Jafari et al. (2006), they had reviewed 28 articles, and found 10 success factors in implementing the ERP in Malaysian companies which are:

(1) Top management support,

(2) Clear goals and objectives,

(3) Communication,

(4) Effective project management,

(5) Business process reengineering,

(6) Data accuracy and integrity,

(7) Suitability of software and hardware,

(8) Vendor support,

(9) Education and training, and

(10) User involvement.

As reviews reveal, in the present literature reviews about ERP, on the whole, 51 success and 20 failure factors have been recognized and analyzed. Further investigations show that only 15 success and 8 failure factors out of the above totals have been dealt with and referred to more frequently in the previous studies. Appendix A of this research gives a summary of the most cited success factors in ERP.

The most important Success Factors (SFs), which have been cited by sufficient number of authors, have been prioritized based on the success factors in the ERP implementation. These factors, i.e. top management support, project management and education and training are sequentially considered as the most essential success factors cited in the literature reviews.

\subsection{Methodology}

The questionnaire which was developed for the first part of this research was based on the 15 success and 8 failure factors respectively that were found during reviewing the literatures. The utilized scale in this survey was a 4 Level Likert Scale. The questionnaire was checked and reviewed by ERP professionals and relevant academic specialists to find out the rate of the validity of the questions and the expected answers. For this end, ten participants were engaged to answer the initial sample questionnaire to arrive at its reliability for the final actual task. The reliability was based on Cronbach's Alpha formula which came to 0.76 . In comparison to the initial sampling, the final task size was calculated to arrive at $n=156$. In order to check the efficiency of the variables, a sample T-test method was applied, in which the null hypothesis was H0: $\mu<2.4$ and the alternative hypothesis was H1: $\mu \geq 2.4$. The statistic test was (Note 1):

\subsection{Data Analysis}

$$
t=\frac{\bar{x}-2.4}{s / \sqrt{n}} .
$$

The table 6 displays the success factors in ERP implementation sorted by their importance degree based on the results of the users' answers to the questionnaires. In this table (Table 6), a list of the first 10 important factors of success in the ERP in Malaysian SMEs, the most important factors are shown in order as below: (1) Implementing team works and composition of team, (2) Effective training of users, (3) Open and honest communication, (4) Group structure, (5) Other departments' participation, (6) Reasonable expectation with definite targets, (7) Top management involvement, (8) Cooperation between enterprise and Software Company, (9) Project management, and (10) Effective decision-making. Two of the factors on top, i.e. "Effective training of the users" and "Team works", are considered as the most important and effective of the factors that immensely affect the success of ERP system implementation in Malaysian SMEs.

On the other hand, table 2 shows that, from the ERP users' point of view, the most important and effective variable among the failure factors in Malaysian SMEs is the 'Poor planning or poor management' which has the highest average of 2.782. The calculated statistics for this is $t=2.7$, so: $t=2.7>\operatorname{tn}-10=1.67$

As a result, the variable 'Poor planning or poor management' is statistically significant which, in turn supports 
the previous literatures. This variable has also been one of the most important failure factors in ERP system implementation in other researches. The second significantly meaningful variable is 'Inappropriate training methods' which enjoys an average of 2.364. The rest of the variables in the research, apparently, do not have significant effect on the failure of the ERP implementations in Malaysia.

\subsection{Findings and Results}

As the above success and failure factors findings reveal, and from the viewpoints of the ERP users in different Malaysian SMEs, it can be concluded that training possesses an important position among the most important success and failure factors in ERP. Therefore, the next phase of this study will attempt to find out the most effective ERP training methods, as stated in literature review, based on the data collected from ERP users in SMEs in Malaysia.

\section{Phase two}

\subsection{Introduction}

The extant literature on ERP and established business practices adopted by the majority of ERP vendors and trainers suggest that the effective implementation and operation of ERP systems require a training model in an extensive period of time which utilizes external consultants as part of the training and a quintessential condition (Koh, Gunasekaren, \& Cooper, 2009). Having an appropriate and effective training method is one of the most important concerns among the ERP success and failure factors (Sumner, 1999; Kale, 2000). ERP systems like other new technologies in an organization need training of the staff to make them able to manipulate the system in a correct and effective fashion (Koh, Gunasekaren, \& Cooper, 2009). Most of the previous researches support training as an essential factor in implementing and operating ERP systems successfully. In this regard, Dowlatshahi (2005) believes that ERP systems like other new technologies utilized in an organization necessitate the requirement of training for the staff to enable them to manipulate the installed system correctly and effectively.

Therefore, ERP training system is considered to be the most vital factor in successful ERP implementations. A joint study by Botta-Genoulaz \& Millet (2006) reveals that ERP training contributes to the optimization of ERP system. Their study was based on 217 survey questionnaires distributed among selected manufacturing firms. Further 14 qualitative interviews followed the questionnaires to increase the validity of the interpreted responses and consequently their arrived results. The outcomes supported the importance of training as a key component to master the software and its vitality for realization of the full potential of an ERP system. Another study conducted by Choi, Kim and Kim (2007) displays the benefits of training which are more than simply learning how to use the software or hardware in a system. They argue that effective training is invaluable factor in paving the way to a positive attitude toward the system and boosting the acceptance of the users.

There are some SME-specific ERP systems vendors who suggest, or even prescribe, an apparently restricted training period in comparison to other ERP vendors and trainers. This kind of insufficient and limited investment for training the staff is considered as a factor which undermines the significance of the success of SME-specific ERP systems' project (Koh, Gunasekaren, \& Cooper, 2009). Laukkanen, Sarpola and Hallikainen (2007) concluded from the results of a study that SMEs have natural tendency toward "a poverty of knowledge" concerning ERP systems, hence, the training of users should be given serious heed in small enterprises. In this regard, Sun, Yazdani and Overend (2005) conducted a relevant study through which they concluded that the critical success factors entitled "people", including training, are to be given the highest priority in ERP implementation. They assert that all other factors, namely, data, process, management and organization ultimately depend on people, i.e. the staff and users.

When the applied training method is not strong enough and effective, it can result in weak ERP implementation and final failure. As a result of the weak training method, the staff and managers cannot gain sufficient familiarity with the way the ERP system functions in the organization. Weak and inefficient training methods can lead to the disappointment of the users who want to work with these systems (Choi, Kim, \& Kim, 2007). On the contrary, when a company obliges or invites the staff to participate in special and proper training courses, their confidence on the reliability of the organization in saving their jobs will increase and their negative concerns about the probable loss of their jobs will decrease, hence resulting in the rise of the work efficiency accordingly (Esteves, Pastor, \& Casanovas, 2002). Besides, since the ERP final users do not have any expertise in programming or system analysis, effective and proper staff training can create a positive attitude in staff toward the target system. This scales up the users' knowledge of the system and, consequently, their skills in manipulating the system in effective ways. Furthermore, it prepares the users to admit and comprehend the system trends sufficiently (Choi, Kim, \& Kim, 2007). 
One of the advantages of SME-specific ERP systems is that they can be successfully implemented and operated with a minimum investment in formal training environment without need for additional consultancy. The studies and the resulted findings support that a successful training model is usually based on three key vital factors, namely "the design of the system", "the previous experience of users with ERP systems", and "the support tools" provided by vendors (Koh, Gunasekaren, \& Cooper, 2009). If a firm or company needs consultancy regarding the ERP system - either for staff training or operating the ERP system - the company or firm should pay an amount of \$150-225 per hour for consultancy services (Wheatley, 2000). Therefore, staff training is vital not only for successful and effective performance of the tasks, but also for reduction of the consultancy requirements, and ultimately expenses.

According to the advices and opinions of most of the ERP consultants, success seeking firms that apply the ERP to raise their efficiency should 'allocate 10 to 15 percent of their ERP budget to training' (Kale, 2000). Regarding the importance of a proper training system, Koch (1996) believes that 30 to 40 percent of workers have to be trained to be able to run and manage the sustainability of the new system (Koch \& Christopher, 1999).

It should be noted that training system is financially one of the expensive parts of the ERP implementations (Esteves, Carvalho, \& Santos). However, not only have most companies a low budget for training system and a small number of the trainers (Yaverbaum \& Nosek, 1992), but also 'it is difficult for the trainers or consulters to pass on the awareness to the employees in a short period of time' (Bingi, Sharma, \& Godla, 1999). Therefore, following a constant ERP training method, which is more proper and distributed in long term schedules, is essential and vital for the success and survival of the companies (Kale, 2000).

\subsection{Training Method and Features}

According to the reviewing the literatures, myriad number of companies provides ERP training methods which include: Lecturing, On-the-job training (OJT), Self direct training, Simulation, Computer based learning, and CD-ROM and laser disk learning. Nearly none of these methods have been considered by ERP implementers as a proper and acceptable training method.

However, a review of the approaches applied to training and consultancy accepted by different ERP vendors and trainers reveals that the training methods employed by one firm differs completely from the models and techniques utilized by other companies (Koh, Gunasekaren, \& Cooper, 2009). There are some large ERP vendors such as SAP, that prescribe a "continuous process of lifelong learning" as the recommended training approach (www.SAP.com). While some other major ERP vendors provide a wider-range of training courses and techniques to guarantee the effective and successful implementation and operation of their own ERP systems. The vendors of the latter group prescribe some techniques like e-learning, on-site training, classroom training, and consultancy as part of the employed methods (Koh, Gunasekaren, \& Cooper, 2009).

Concerning the training forms that they have to pursue, companies have a few options to choose from. Usually vendors offer training modules that aim at the staff as end users. Such modules rarely cover the necessary trainings and information for proficient operation of the ERP system which requires proficient experts to monitor or handle. This kind of proficiency training, as extra requirement for training proficient staff, is usually too expensive, especially for small firms. Nonetheless, a combination of these techniques is required to guarantee the success of ERP project, which directly opposes "the assertions of the case company" (Koh, Gunasekaren, \& Cooper, 2009). In order to reduce the training problems, ERP training companies have developed Internet-based training programs for some organizations with different locations in various areas. Such companies, utilizing Internet-based training programs, have significantly decreased training costs and increased the employee mastery of the system instead. Table 3 depicts the features of different ERP training methods collected from various literature reviews (Noudoostbeni, Yasin, \& Jenatabadi, 2009).

\subsection{Methodology and Analysis of Data}

As the results of the study in the previous phase (phase one) displayed, a sound investment, application of effective training methods and enforcement of suitable company policies can be important stimulants to encourage the staff to co-work as members of a team to guarantee the ERP implementation success in SMEs in Malaysia.

In order to identify the best training method to prepare the staff as ERP users, another questionnaire was designed and distributed among the participants and they were asked to evaluate different methods of training in ERP. Table 4 presents the percentages of the application of different methods in ERP training in Malaysian SMEs.

As Table 4 shows, the most common methods, used frequently in ERP trainings in Malaysian SMEs, include: 
Lecturing (23\%), On-the-job training (OJT) (17\%), and Computer-based learning (17\%). However, based on the ERP users' and managers' viewpoints, the application of the above mentioned methods do not guarantee the success of the ERP implementation in Malaysian SMEs.

\subsection{Results}

In this phase of the study, based on the ERP training features and analysis of the gathered data from the Malaysian final users' of the ERP, it can be concluded that two of the above methods, i.e. (1) One-the-job training (OJT) and (2) Computer-based learning, can be selected as the most proper and effective ERP training methods.

\section{Phase Three}

In this section, a new ERP training system has been proposed to promote the adoption of ERP among the Malaysian SMEs in an easier and more understandable manner. The suggested system contains a set of simple guidelines, which have been formulated on basis of the best practices of ERP adoption. Besides that, the system allows the authorized users to sign in through the IP address of their computer and get involved in the community activities such as sharing and exchanging ideas on ERP modules through the available message boards and audio files. At the last stage to confirm that the developed system meets the user requirements, a user system evaluation was done.

\subsection{The Recommended Method}

In order to promote the new training method among the selected Malaysian SMEs, this system intended to connect the staff through a network of colleagues to enable discussing and sharing knowledge about ERP system to help the ERP staff with realizing its significance. As mentioned in the previous section, On-the-job training $(17 \%)$, and Computer-based learning (17\%) are two of the methods used by the majority of the staff of the selected ERP companies in Malaysia. Therefore, the recommended method in this research is a method created from a combination of these two training methods.

\subsection{The Recommended Training Method Procedure}

The proposed system develops on the concept of knowledge sharing which results from infusion of On-the-job training and Computer-based learning. In this kind of system, each ERP pages is displayed as a separate window connected to its own database. The access to this system is feasible through either clicking the middle button on the mouse or a hot key (shortcuts) that can be defined by user such as pressing a key or a combination of keys (Alt, Shift, Ctrl + one key) on keyboard to communicate the instruction to the system. The specifically defined hot keys, ambiguous or unknown to the authorized user, can be disclosed and clarified to them by the authorized personnel. Since this method is based on knowledge sharing, the verified experiences of the other users are also available on the system request fields in parallel to the definitions provided by the software. Moreover, the user is linked to an audio database, through which s/he have access to the audio files that have already been recorded by the other users and uploaded on the database after the authorized person in charge's verification of the content and reliability of the file. The figure 1 illustrates the flowchart of this system.

As it is shown in figure 1, both the opened page and the field position can be recognized by the system. Therefore, the system, based on the clicked position by the ERP user, can disclose the related data upon user's request.

The new ERP training system was suggested and the respondents were asked to choose whether they agreed on setting up the new ERP training system. For doing this purpose a questionnaire were distributed to the ERP staffs. The answers all are shown that the respondents agreed on setting a new ERP training system.

An arrangement test was carried out to test the server and client systems as a whole when the entire training system is finish and installed. It was checked to ensure that it works perfectly once it's uploaded to the server. It also tested whether there are any broken links in the entire company intranet networks since it's transferred from the local host to another domain hosting company.

\subsection{User Feedback}

Finally, users participate in the user testing to confirm that the developed system meets the user requirements. User testing shall be done in a simulated 'real' user environment with the users using simulated or real target platforms and infrastructures. Therefore user testing was done on the researcher's laptop with a personal web server. During the user testing stage, ten users tested the new ERP training system and were required to fill in the system evaluation form as shown in Appendix B. The users' feedback is summarized in table 5. 


\section{Challenges and Problems Encountered}

There were some impediments and problems encountered during data collection. In order to reduce the challenges and resolve the problems as much as possible, some trustable solutions were resorted. Some of the problems and the relevant approaches taken for the resolution during the data gathering are as following.

In order to find some appropriate companies for the study, more than 70 letters were sent to various SMEs in Malaysia, but the number of the responses for collaboration was disappointing. To solve this problem, we asked some friends and acquaintances to introduce us to some relevant companies. The result was comparably better, supporting the idea that it is better to be introduced to a company by someone before asking them for help.

During the process of data gathering, we realized that some of the involved SMEs staff did not have good command of English to help us with the questionnaire, as the language of our questionnaires required. As a result, they had problem to comprehend the questions and answer them appropriately. Therefore, to solve this problem, we were obliged to ask a local student to translate the questionnaire into Bahasa Melayu, the national and official language of Malaysia.

\section{Conclusion}

Since the ERP training is a field that constantly evolves, not much updated study is available in the market. As stated in the previous section, there were some difficulties in doing this research. However, it can be concluded that Malaysian SMEs have started to adopt ERP and, subsequently, its training systems in their companies at a certain degree, but it has been growing rapidly in the recent few years. However, by doing this research and developing the proposed ERP training system, a better understanding of the status of the ERP adoption in Malaysian SMEs can be achieved. This was the main objective of the current research which is expected to be fulfilled.

\section{References}

Al-Mashari, M., Zairi, M., \& Okazawa, K. (2006). Enterprise Resource Planning (ERP) implementation: A useful road map. Management and Enterprise Development, 169 - 180.

Bendoly, E., \& Jacobs, F. (2004). ERP architectural/operational alignment for order-processing performance. International Journal of operations and production management, 24 (1), 99-117.

Bingi, P., Sharma, M., \& Godla, J. (1999). Critical Issues Affecting an ERP Implementation. Information Systems Management, 16, 7-15.

Botta-Genoualz, V., \& Millet, P. A. (2006). An investigation into the use of ERP systems in the service sector. International journal of production economics, 99 (1), 202-221.

Bullen, C. V. (1995). Productivity CSFs for Knowledge Workers. The Executive's Journal: Information Strategy, 14-20.

Choi, D. H., Kim, J., \& Kim, S. H. (2007). ERP training with a web-based electronic learning system: The flow theory perspective. Human-Computer Studies, 223-243.

Dowlatshahi, S. (2005). Strategic success factors in enterprise resource planning design and implemenation: a case-study approach. International journal of production research, 43 (18), 3745-3771.

Esteves, J., Carvalho, J., \& Santos, A. (2001). Towards an ERP life-cycle costs model. Information Resources Management Association (IRMA) International Conference, (pp. 51-62). Toronto.

Esteves, J., Pastor, J., \& Santos, A. (2002). A Framework Proposal for Monitoring and Evaluating Training in ERP Implementation Projects. Technical Research, Toronto.

Huang, Z., \& Palvia, P. (2001). ERP implementation issues in advanced and developing countries. Business Process Management, 7, 276-284.

Jafari, S. M., Osman, M. R., Yusuf, R. M., \& Tang, S. H. (2006). ERP systems implementation in Malaysia: the importance of critical success factors. Engineering and Technology, 3, 125-131.

Jing, R., \& Qiu, X. (2007). A study on critical success factors in ERP systems implementation. International Conference of service systems and service management. Chengdu: IEEE.

Kale, V. (2000). Implementing SAP R/3: the guide for Business and Technology Managers. Sams Publishing.

Ketikidis, p., Koh, S. L., Dimitradis, N., Gunsekaran, A., \& Kehajova, M. (2008). The use of information systems for logistics and supply chain management in south east Europe: current statuse and future direction. 
International Journal of Management Science, OMEGA 36, 36 (4), Volume 36, Issue 4, August 2008, Pages 592-599.

Koch. (1999). The most important team in history. Retrieved Feb 11, 2010, [Online] Available: www.cio.com/archive/101599/erp1.html

Koh, S. L., Gunasekaren, A., \& Cooper, J. R. (2009). The demand for training and consultancy investment in SME-specific ERP systems implementation and operation. International journal of production economics, 122, 241-254.

Laukkanen, S., Sarpola, S., \& Hallikainen, P. (2005). ERP system Adoption-Does the size matter? International Conference on system sciences (p. 226). Hawaii: IEEE Computer Society .

Laukkanen, S., Sarpola, S., \& Hallikainen, P. (2007). Enterprise size matters: objectives and constraints of ERP adoption. Journal of enterprise information management, 20 (3), 319-334.

Loh, T., \& Koh, S. (2004). Critical elements for a successful enterprise resource planning implementation in small- and medium-sized enterprises. International journal of production research, 42 (17), 3433-3455.

Martin, M. H. (1998). An ERP strategy. Fortune, 149-151.

MITI, Ministry of International Trade \& Industry. (2002). Retrieved Feb 11, 2010, from Malaysia, Policies, Incentives and Facilities, [Online] Available: http://www.smidec.gov.my/

Nah, F. F., \& Lau, J. L. (2001). Critical success factors for successful implementation of enterprsie systems. Business Process Management, 285-296.

Noudoostbeni, A., Yasin, N. M., \& Jenatabadi, H. S. (2009). A mixed method for training ERP systems based on knowledge sharing in Malaysian Small and Medium Enterprises (SMEs). International Conference on Information Management and Engineering (pp. 244-247). Kuala Lumpur: IEEE.

Shou, Y., \& Ying, Y. (2005). Critical failure factors of information system projects in Chinese enterprises . International Conference on service systems and service management. Chongqing: IEEE.

Sumner, M. (1999). Critical success factors in enterprise wide information management systems projects. American conference on information systems. Milwaukee.

Sun, A., Yazdani, A., \& Overend, J. (2005). Achivement assessment for enterprise resource planning (ERP) system implementations based on critical success factors (CSFs). International journal of production economics, 98 (2), 189-203.

Trunick, P. A. (1999). ERP: promise or pipe dream? Transportation and Distribution, 40, 23-26.

Umble \& Michae. (2002). Avoiding ERP implementation failure. Industrial Management, 44 (1), 25-34.

Umble, E. J., Haft, R. R., \& Umble, M. M. (2003). Enterprise resource planning: implementation procedures and critical success factors. European journal of operational management, 146, 241-257.

Wheatley, M. (2000). ERP training stinks. ERP training stinks. CIO, 13 (16), 86-96.

Woo, H. (2007). Critical success factors for implementing ERP: the case of a chinese electronics manufacturer. Journal of manufacturing technology management, 18 (4), 431-442.

Yaverbaum, G. J., \& Nosek, J. (1992). Effects of information system education and training on user satisfaction. Information \& Management, 2, 217-225.

Yi, F. S., \& Chyan, Y. (2010). A structural equation model for analyzing the impact of ERP on SCM. Expert systems with application, 37 (1), 456-469.

Yongyi, S., \& Ying, Y. (2005). Critical failure factors of information system projects in chinese enterprises. 2, pp. 823 - 827. Hangzhou: IEEE.

Yongyi, S., \& Ying, Y. (2005). Critical Failure Factors of Information system projects in chinese Enterprises.

\section{Note}

Note 1. T-test formula 
Table 1. Research contrast in three phases

\begin{tabular}{|c|c|c|c|}
\hline & Phase I & Phase II & Phase III \\
\hline $\begin{array}{l}\text { Success Factors } \\
\quad 15 \text { factors } \\
\text { Failure Factors } \\
\quad 8 \text { factors }\end{array}$ & $\begin{array}{l}\left\{\begin{array}{l}\text { Effective Training of Users } \\
\text { Implementing Team Work }\end{array}\right. \\
\left\{\begin{array}{l}\text { Poor Planning and Poor Management } \\
\text { Unsuitable Training Methods }\end{array}\right.\end{array}$ & $\begin{array}{l}\text { Comparison between different ERP } \\
\text { training methods } \\
\left\{\begin{array}{c}\text { 1. On-the-Job Training (OJT) } \\
+ \\
\text { 2. Computer-Based learning }\end{array}\right.\end{array}$ & $\{$ An ERP mixed method training system \\
\hline Results & $\begin{array}{l}\text { Training is the most important success and failure } \\
\text { factor in implementing ERP systems in Malaysian } \\
\text { SMEs }\end{array}$ & $\begin{array}{c}\text { On-the-job training and computer based learing } \\
\text { methods are useful and effective methods in } \\
\text { training ERP users }\end{array}$ & $\begin{array}{l}\text { A more effective ERP training system based on } \\
\text { the achieved results from previous phases in } \\
\text { Malaysian SMEs }\end{array}$ \\
\hline
\end{tabular}

Table 2. Failure Factors by Degree of Importance in ERP Implementation

\begin{tabular}{||l|c|c|c||}
\hline \multicolumn{1}{|c|}{ Item } & Mean & STD & T-test \\
\hline 1.Inappropriate training methods & 2.727 & 1.027 & 2.364 \\
\hline 2.Poor planning or poor management & 2.782 & 1.049 & 2.700 \\
\hline 3.Change in business goals during the project & 2.545 & 0.997 & 1.082 \\
\hline 4.Lack of business management support & 2.400 & 1.082 & 0.000 \\
\hline 5.Hostile company culture & 2.455 & 1.051 & 0.385 \\
\hline 6.Improper reporting structure & 2.455 & 0.939 & 0.431 \\
\hline 7.Inappropriate level of management commitment & 2.145 & 0.970 & -1.946 \\
\hline 8.Political pressures & 1.909 & 1.005 & -3.622 \\
\hline \hline
\end{tabular}

Table 3. ERP training Methods and features

\begin{tabular}{|c|c|c|c|c|c|}
\hline \multicolumn{6}{|c|}{ ERP Training Methods Features } \\
\hline $\begin{array}{l}\text { Computer- } \\
\text { Based } \\
\text { Training }\end{array}$ & CD-ROM & Lecture & $\begin{array}{l}\text { Self-Directed } \\
\text { Learning }\end{array}$ & $\begin{array}{l}\text { On the-Job- } \\
\text { Training }\end{array}$ & Simulation \\
\hline $\begin{array}{c}\text { Computer } \\
\text { provides the } \\
\text { learning stimulus }\end{array}$ & $\begin{array}{l}\text { Interaction with } \\
\text { training } \\
\text { material through } \\
\text { using joystick }\end{array}$ & $\begin{array}{l}\text { Communication } \\
\text { through } \\
\text { speaking }\end{array}$ & $\begin{array}{l}\text { Employees are } \\
\text { responsible }\end{array}$ & $\begin{array}{l}\text { Learning through } \\
\text { observing } \\
\text { peers }\end{array}$ & $\begin{array}{l}\text { Represent a real } \\
\text { life situation }\end{array}$ \\
\hline $\begin{array}{l}\text { Computer } \\
\text { analyzes the } \\
\text { responses }\end{array}$ & \multirow{5}{*}{$\begin{array}{l}\text { Interaction with } \\
\text { training } \\
\text { material through } \\
\text { using touch-screen } \\
\text { monitor }\end{array}$} & Cheap & $\begin{array}{l}\text { Learning without } \\
\text { an instructor }\end{array}$ & $\begin{array}{l}\text { Learning through } \\
\text { observing managers } \\
\text { performing }\end{array}$ & $\begin{array}{l}\text { Developing } \\
\text { managerial } \\
\text { skills }\end{array}$ \\
\hline \multirow{4}{*}{$\begin{array}{c}\text { Computer provide } \\
\text { feedback to the } \\
\text { trainee }\end{array}$} & & Less time & $\begin{array}{c}\text { Learning process } \\
\text { controlled } \\
\text { by the trainee }\end{array}$ & $\begin{array}{c}\text { Useful for training } \\
\text { new } \\
\text { hired employee }\end{array}$ & $\begin{array}{l}\text { Fidelity to the } \\
\text { equipment } \\
\text { that trainee will } \\
\text { encounter } \\
\text { on the job }\end{array}$ \\
\hline & & $\begin{array}{c}\text { For large group of } \\
\text { trainees }\end{array}$ & $\begin{array}{l}\text { Encourage new } \\
\text { employees to learn } \\
\text { actively }\end{array}$ & \multirow{3}{*}{$\begin{array}{l}\text { Less investment in } \\
\text { time and money for } \\
\text { material }\end{array}$} & $\begin{array}{l}\text { Fidelity to the } \\
\text { situation } \\
\text { that trainee will } \\
\text { encounter } \\
\text { on the job }\end{array}$ \\
\hline & & Supporting other & $\begin{array}{l}\text { Gaining better } \\
\text { understanding of } \\
\text { working place }\end{array}$ & & \multirow{2}{*}{ Expensive } \\
\hline & & methods & $\begin{array}{l}\text { Reducing the costs } \\
\text { associated with } \\
\text { traveling }\end{array}$ & & \\
\hline
\end{tabular}


Table 4. Training Methods in a Descending Order of Most Used

\begin{tabular}{|l|c|}
\hline \multicolumn{2}{|c|}{ ERP training methods } \\
\hline Lecturer & $23.7 \%$ \\
\hline on-the-job training(OJT) & $17.8 \%$ \\
\hline Computer-Based learning & $17.2 \%$ \\
\hline Team training & $16.6 \%$ \\
\hline Self-direct learning & $7.7 \%$ \\
\hline Apprenticeship & $3.6 \%$ \\
\hline Simulation & $3.6 \%$ \\
\hline Action learning & $3.6 \%$ \\
\hline Internet or web-based training & $2.4 \%$ \\
\hline Behavior modeling & $1.2 \%$ \\
\hline Distance learning & $1.2 \%$ \\
\hline Interactive video & $0.6 \%$ \\
\hline Virtual reality & $0.6 \%$ \\
\hline Adventure learning & $0 \%$ \\
\hline CD-ROM and leaser disk & $0 \%$ \\
\hline
\end{tabular}

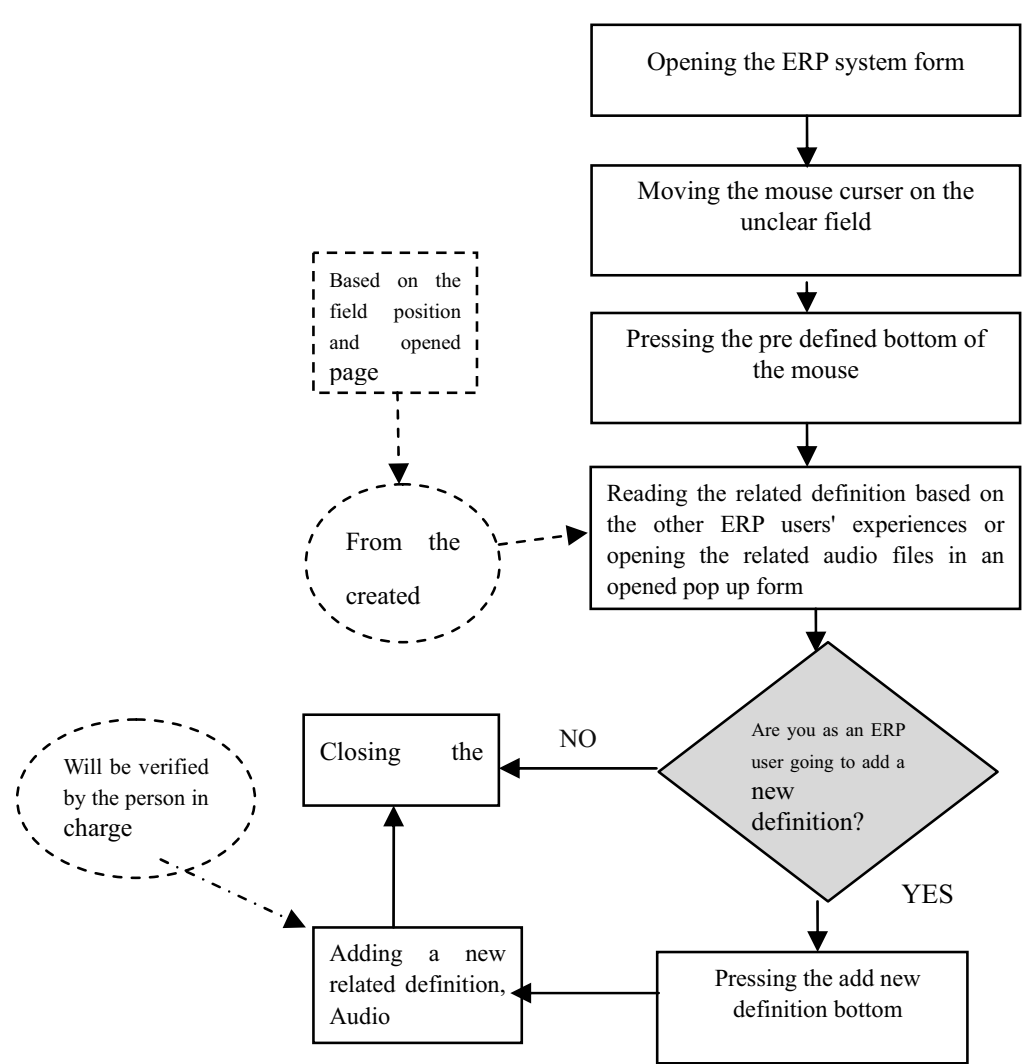

Figure 1. ERP Mixed Method Training Procedure

The Recommended Training Method Procedure 
Table 5. Summary of User Feedback

\begin{tabular}{|c|c|}
\hline Question & $\begin{array}{l}\text { Feedback } \\
\end{array}$ \\
\hline How user friendly is the application? & $\begin{array}{l}\text { All the respondents agreed that the system is easy } \\
\text { to use. Five respondents stated that the user } \\
\text { friendliness is good and two stated that it is } \\
\text { Average. Therefore it can be summarized that this } \\
\text { system is easy to use. }\end{array}$ \\
\hline How is the user interface and layout design? & $\begin{array}{l}\text { Four respondents stated that the user interface is } \\
\text { good and easy to understand. Three respondents } \\
\text { stated that the user interface can improve to look } \\
\text { better. }\end{array}$ \\
\hline How is the color combination of ERP training system? & $\begin{array}{l}\text { Seven respondents stated that the color } \\
\text { combination is good. It's pleasant to view } \\
\text { because of the soft gray color scheme. }\end{array}$ \\
\hline How is the text style and text size? Was it easy to read? & $\begin{array}{l}\text { All the respondents were satisfied with the text } \\
\text { style and size because the text is easy to read. }\end{array}$ \\
\hline $\begin{array}{l}\text { What do you think about the contents in ERP training } \\
\text { system? }\end{array}$ & $\begin{array}{l}\text { Four of the respondents stated that the content of } \\
\text { the system is average, while two stated that it is } \\
\text { poor and need more improvement. }\end{array}$ \\
\hline Please rate the usefulness of the ERP training system. & $\begin{array}{l}\text { Five of the respondents agreed that the system is } \\
\text { useful for them because they can get all the } \\
\text { frequent questions on their PC without asking } \\
\text { anyone. Three respondents stated the system is } \\
\text { usefulness is good but it needs to improve more. }\end{array}$ \\
\hline $\begin{array}{l}\text { Please rate your overall view for the ERP training } \\
\text { system. }\end{array}$ & $\begin{array}{l}\text { Overall, all the respondents rated that the system } \\
\text { is good. }\end{array}$ \\
\hline Comments \& Suggestions & $\begin{array}{l}\text { Only three of the respondents suggested to } \\
\text { improve the user interface and also one of them } \\
\text { suggested that it would be better if the system } \\
\text { shown other opinion in a new pop-up. }\end{array}$ \\
\hline
\end{tabular}

Table 6. Success Factors by Degree of Importance in ERP Implementation

\begin{tabular}{||l|l|l|c||}
\hline \multicolumn{1}{|c|}{ Item } & Mean & STD & T-test \\
\hline 1. Top management involvement & 3.109 & 0.737 & 7.134 \\
\hline 2. Effective training of users & 3.218 & 0.686 & 8.850 \\
\hline 3. Implementing team's teamwork and composition & 3.255 & 0.584 & 10.846 \\
\hline 4. Other departments' participation & 3.145 & 0.756 & 7.316 \\
\hline 5. Funds support & 2.891 & 0.737 & 4.939 \\
\hline 6. Cooperation between enterprise and software company & 3.073 & 0.716 & 6.965 \\
\hline 7. Reasonable expectation with definite targets & 3.091 & 0.701 & 7.308 \\
\hline 8. Open and honest communication & 3.200 & 0.704 & 8.422 \\
\hline 9. Group structure & 3.109 & 0.629 & 8.364 \\
\hline 10. Project management & 3.000 & 0.667 & 6.675 \\
\hline 11. Enterprise information management & 2.745 & 0.799 & 3.208 \\
\hline 12. Outside competition pressure & 2.291 & 0.916 & -0.883 \\
\hline 13. Service of supplier & 2.418 & 0.937 & 0.144 \\
\hline 14. Software development, testing and troubleshooting & 2.927 & 0.813 & 4.809 \\
\hline 15. Effective decision-making & 3.000 & 0.839 & 5.304 \\
\hline
\end{tabular}




\section{Appendix A}

Success Factors in ERP Implementation

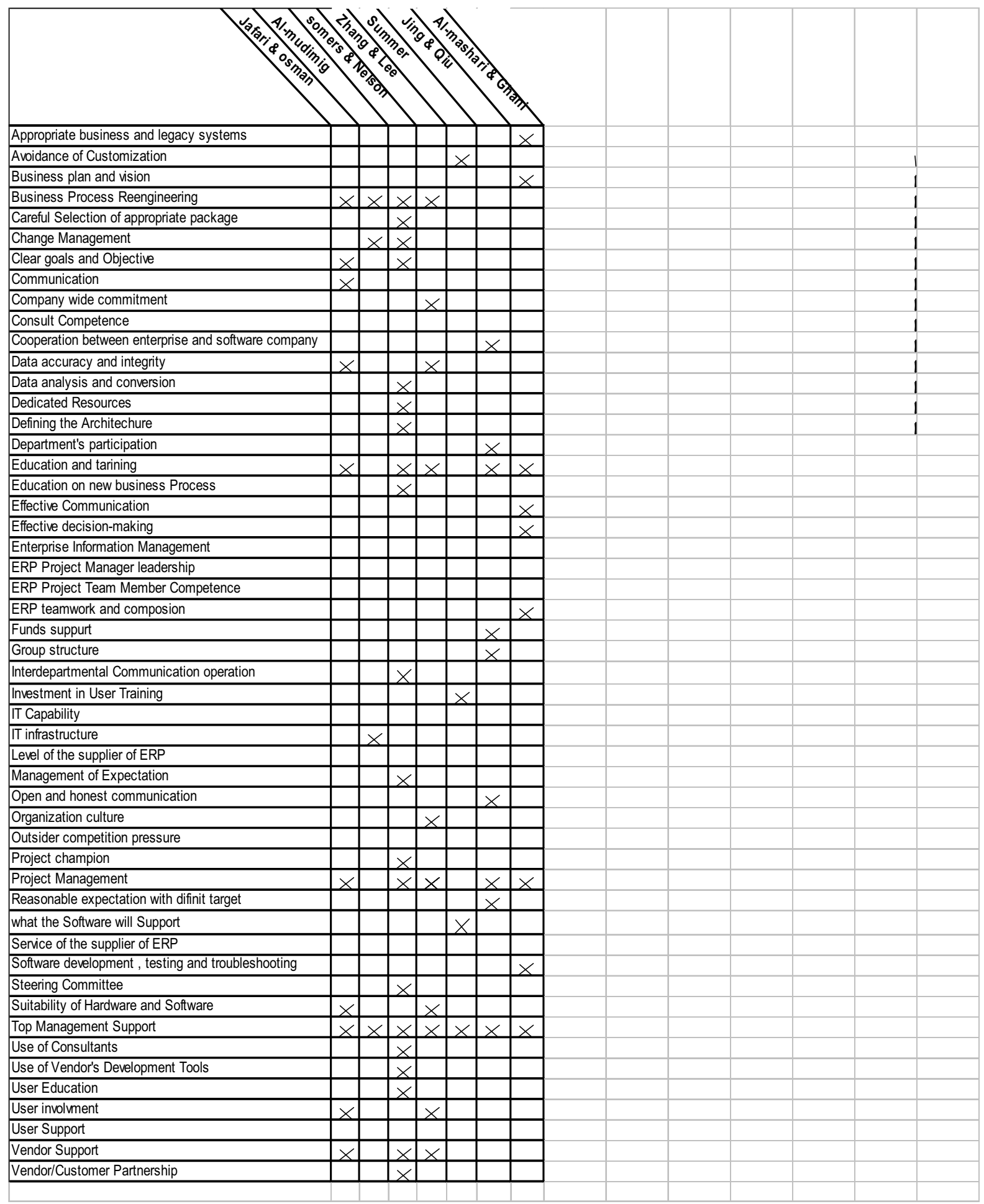




\section{Appendix B}

ERP training Evaluation Form

Evaluation done by:

Evaluation Date:

Very good Poor Average Good Excellent

1. How user friendly is the application

2. How is the user interface and layout design?

3. How is the color combination of ERP training system?

4. How is the text style and text size? Was it easy to read?

5. What do you think about the contents in ERP training system?

6. Please rate the usefulness of the ERP training system.

7. Please rate your overall view for the ERP training system.

Comments \& Suggestions: 